\title{
Effect of Welding Parameters on the Peak Load and Energy Absorption of Low-Carbon Steel Resistance Spot Welds
}

\author{
M. Pouranvari \\ Materials and Metallurgical Engineering Department, Dezful Branch, Islamic Azad University, 64616-45169 Dezful, Iran \\ Correspondence should be addressed to M. Pouranvari, mpouranvari@yahoo.com
}

Received 18 January 2011; Accepted 8 March 2011

Academic Editors: A. J. Chamkha and P. Dineva

Copyright () 2011 M. Pouranvari. This is an open access article distributed under the Creative Commons Attribution License, which permits unrestricted use, distribution, and reproduction in any medium, provided the original work is properly cited.

Effect of process variables (electrode pressure, holding time, welding current, and welding time) on low-carbon steel resistance spot welds performance has been investigated in this paper. Failure mode, peak load, and maximum energy obtained in tensile-shear test have been used to describe spot welds performance. Excessive electrode pressure can reduce both peak load and maximum energy, considerably. Holding time does not significantly affect peak load and maximum energy for investigated material. Increasing welding time and welding current to some extent increases both peak load and maximum energy. However, excessive welding time and welding current not only do not increase weld nugget size and peak load, but also decrease maximum energy.

\section{Introduction}

For several decades, resistance spot welding has been the dominant process in sheet metal joining. To ensure and maintain structural integrity of finished component under a wide range of operating conditions, for example a crash situation, the remotest possibility of producing even one or two defective welds in a critical component needs to be eliminated. These requirements, coupled with uncertainties about weld quality due to the difficulty of applying nondestructive tests to spot welds, are responsible for the practice of making more spot welds than what is actually needed for maintaining structural integrity. A modern vehicle contains 2000 to 5000 spot welds. Around $20 \%$ to $30 \%$ of these spot welds are due to uncertainty of the quality of spot welds [1]. Significant cost associated with overwelding provides a considerable driving force for optimizing this process.

Therefore, evaluation of spot welding quality is a very important issue in reliability of vehicle and improving the economics of vehicle production. Evaluating spot welds quality requires studying welding process variables and weld performance interrelations. Weld performance characterizations normally refer to static and dynamic strength. Tensileshear test is the most usual test for evaluating spot weld mechanical behavior under static condition both because of its simplicity and because many of spot welded structures are designed to bear tensile-shear loads. Figure 1 shows typical tensile-shear test load-displacement curve for a spot weld, schematically. Most researchers have used peak load $\left(P_{\max }\right)$, extracted from load-displacement plot, to describe spot weld mechanical behavior. However, as Zhou et al. [2] mentioned, maximum energy $\left(W_{\max }\right)$ corresponding to peak load should be used to describe spot weld mechanical behavior, more precisely. $W_{\max }$ shows spot weld energy absorption capability and the higher the $W_{\max }$, the higher the weld reliability is under impact conditions such as accidents.

The objective of the paper is to evaluate effects of welding parameters (welding current, welding time, electrode force, holding time) on the peak load, energy absorption, and failure mode of low carbon resistance spot welds during static tensile-shear test.

\section{Experimental Procedure}

A 0.8 -mm-thick uncoated low-carbon steel of the type used in automotive industry was used in this investigation. Chemical composition of the steel is Fe-0.045C-0.032Si$0.189 \mathrm{Mn}$. Welds were made using a $120 \mathrm{kVA}$ AC resistance spot welder. Mechanical properties of the base metal are given in Table 1.

Resistance spot welding was performed using a PLCcontrolled, $120 \mathrm{kVA}$ AC pedestal-type resistance spot welding 


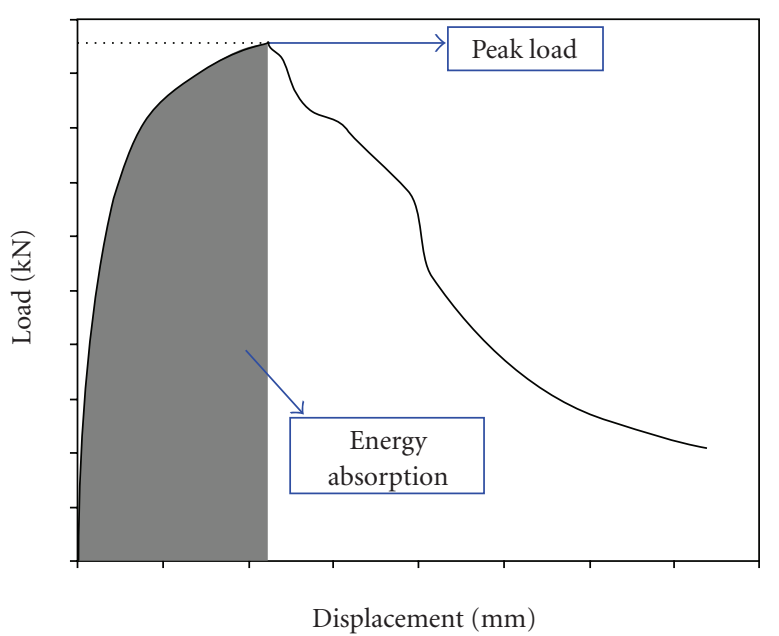

FIgURE 1: Schematic of tensile-shear test load-displacement curve.

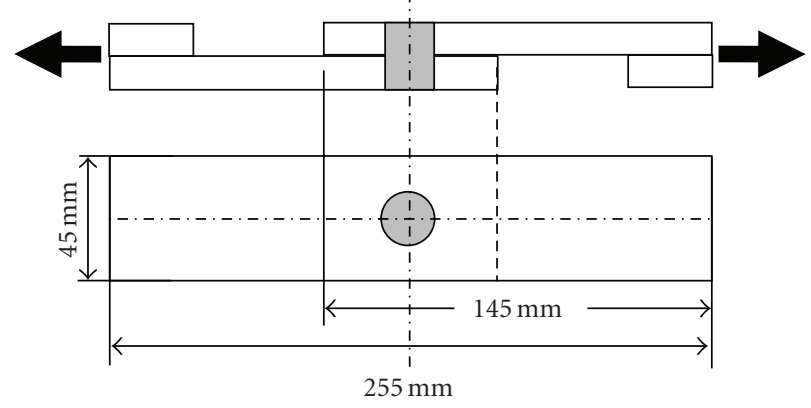

FIGURE 2: Dimensions of tensile-shear test specimens.

TABLE 1: Mechanical properties of the base metal.

\begin{tabular}{lcc}
\hline Yield strength $(\mathrm{MPa})$ & Tensile strength $(\mathrm{MPa})$ & Elongation (\%) \\
\hline 180 & 330 & 48 \\
\hline
\end{tabular}

TABLE 2: Welding schedules.

\begin{tabular}{lc}
\hline Welding current $(\mathrm{kA})$ & $7-11$ \\
Welding time (cycle $)$ & $5-9$ \\
Electrode force (bar) & $2.5-4$ \\
Holding time (cycle) & 5 \\
Squeeze time (cycle) & 40 \\
\hline
\end{tabular}

${ }^{*} 1$ cycle $=50 \mathrm{~Hz}$.

machine. Welding was conducted using a 45-deg truncated cone RWMA Class 2 electrode with 5-mm face diameter.

To study the effects of welding conditions on the weld failure mode, several welding schedules were used. Table 2 shows the process variables used in this study. Critical welding conditions leading to expulsion were recorded. Four samples were prepared for each welding condition including three samples for the tensile-shear test and one sample for metallographic investigation and measurement of weld size.

In order to evaluate the mechanical performance and failure mode of the spot welds, the tensile-shear test

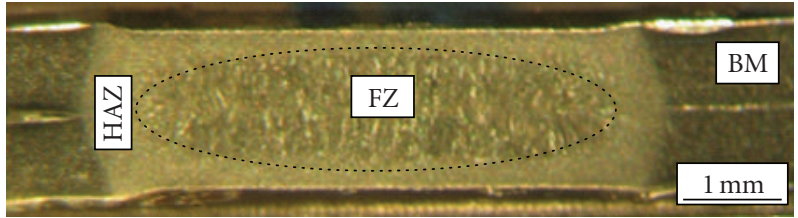

Figure 3: Typical spot weld macrostructure.

was performed. Figure 2 shows the sample dimensions. The tensile-shear tests were performed at a cross-head of $10 \mathrm{~mm} / \mathrm{min}$ with an Instron universal testing machine. Peak load (measured as the peak point in the load-displacement curve) and the failure energy (measured as the area under the load-displacement curve up to the peak load) were extracted from the load-displacement curve (see Figure 1). The data points for peak load and failure energy are averages of the measured values for the three specimens. Failure modes of the spot welded specimens were determined by the examination of the fractured samples.

Samples for the metallographic examination were prepared using standard metallography procedure. $2 \%$ Nital etching reagent was used to reveal the macrostructure and microstructure of the samples. The microstructure of various zones was studied using an optical microscope. Weld nugget (fusion zone) sizes were measured for all the samples on the metallographic cross-sections of the welds.

\section{Results and Discussion}

3.1. Spot Weld Structure and Hardness Profile. Typical macrostructure of a spot weld is shown in Figure 3. As can be seen, it consists of three zones:

(i) weld nugget (melted during welding process and resolidified),

(ii) heat affected zone (HAZ) (not melted but experienced structural changes),

(iii) base metal.

Base metal and weld nugget microstructures are illustrated in Figure 4. The former consists of ferrite matrix and some scattered cementite, while dominant microstructure of the latter is martensite.

A typical spot weld hardness profile is shown in Figure 5. As can be seen in this figure, weld nugget hardness profile consists of three zones: weld nugget, HAZ, and base metal. Weld nugget hardness is twice the value of base metal due to martensite formation in this zone. Weld nugget hardness is almost constant, which shows that although cooling rate is not constant throughout weld nugget, it is fast enough to create a relatively uniform microstructure in this zone. Hardness variation in HAZ is almost linear. HAZ severe microstructure gradient is due to weld cycle thermal gradient which in turn causes high changes in hardness values.

Martensite formation in weld nugget during RSW for low-carbon steels has also been reported by other researchers [2]. Cooling rate is higher for resistance spot welding process, 


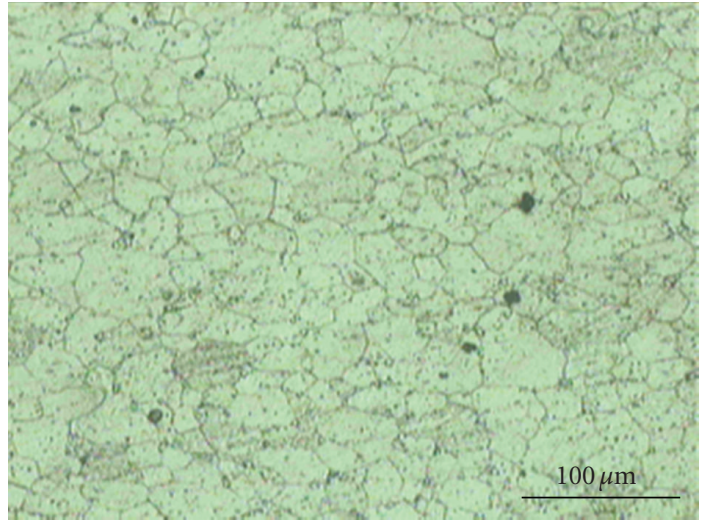

(a)

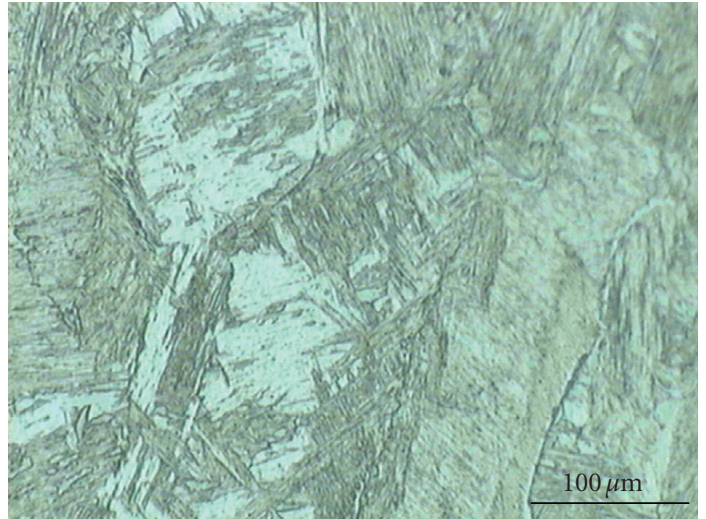

(b)

FIGURE 4: Microstructure of (a) base metal and (b) weld nugget.

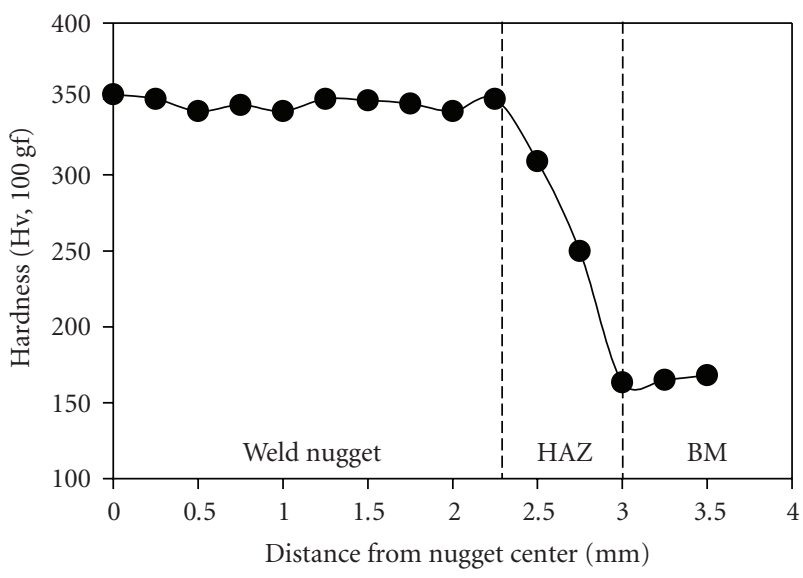

FIGURE 5: Typical hardness profile of spot welds (welding current is $8 \mathrm{kA}$, welding time is 8 cycles, and electrode pressure is $3 \mathrm{bar}$ ).

compared to other fusion welding processes such as arc welding, electron beam welding, and laser beam welding. Volger [3] has reported that RSW cooling rate reaches $1000 \mathrm{Ks}^{-1}$ for zero holding time. Increasing holding time increases cooling rate to more than $10,000 \mathrm{Ks}^{-1}$ because of copper electrode quenching effect [4]. This high cooling rate does not occur in other fusion welding processes. This is due to the presence of water cooled cupper electrodes and their quenching effect as well as short welding cycle.

\subsection{Effect of Process Parameters on Weld Nugget Size. Effect of} electrode pressure, holding time, welding current, and welding time on the fusion zone size has been shown in Figures 6-9. Fusion zone size is one of the most important factors determining mechanical properties, which is governed by process variables. Indeed, weld nugget size is determined by heat input and heat input rate. Generated heat at joint spot is controlled by welding current, welding time, and static (contact) and dynamic electrical resistance. Static electrical resistance is mainly governed by electrode pressure and in turn controls weld nugget formation [5].

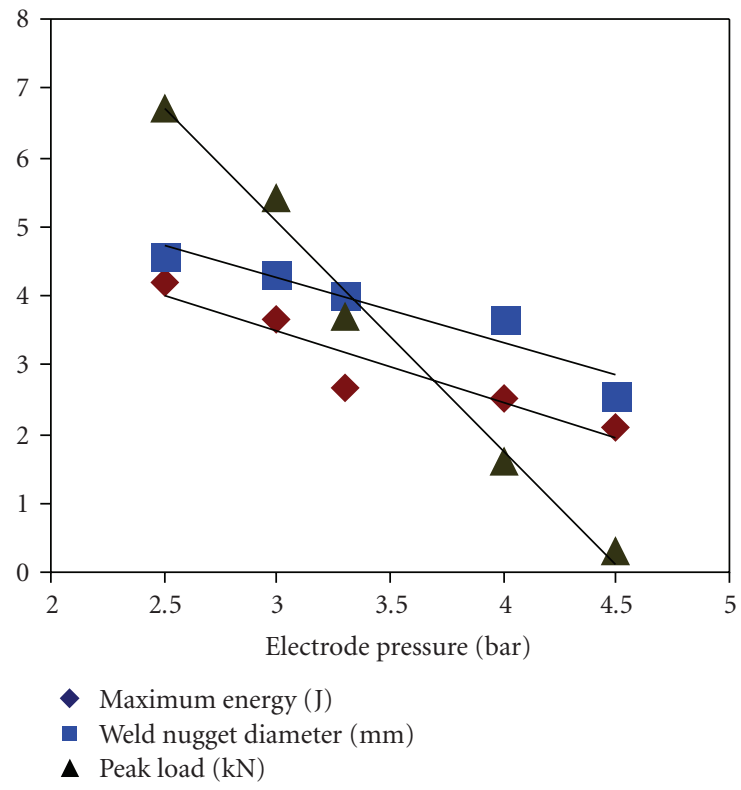

FIGURE 6: Effect of electrode pressure on the weld nugget diameter, peak load and maximum energy, welding current is $8 \mathrm{kA}$, welding time is 8 cycles and holding time is 5 cycles.

As can be seen in Figure 6, weld nugget diameter decreases by increasing electrode force. Electrode force increase decreases material thickness between two electrodes and increases sheet interfacial contact area (by changing the surface roughness). Electric resistance is proportional to conductor's length and reversely related to its cross section area. Therefore, force increase decreases the electric resistance and, thus, reduces the produced heat at the interface.

As can be seen in Figure 7, weld nugget diameter does not change with holding time. Electrode holding time on solidifying weld metal does not affect heating part of thermal cycle and, thus, does not affect generated heat and melted volume. Indeed, increasing welding time and welding current increases heat input and therefore, weld nugget size (Figures 8 and 9). Of course, for a constant time, increasing welding 


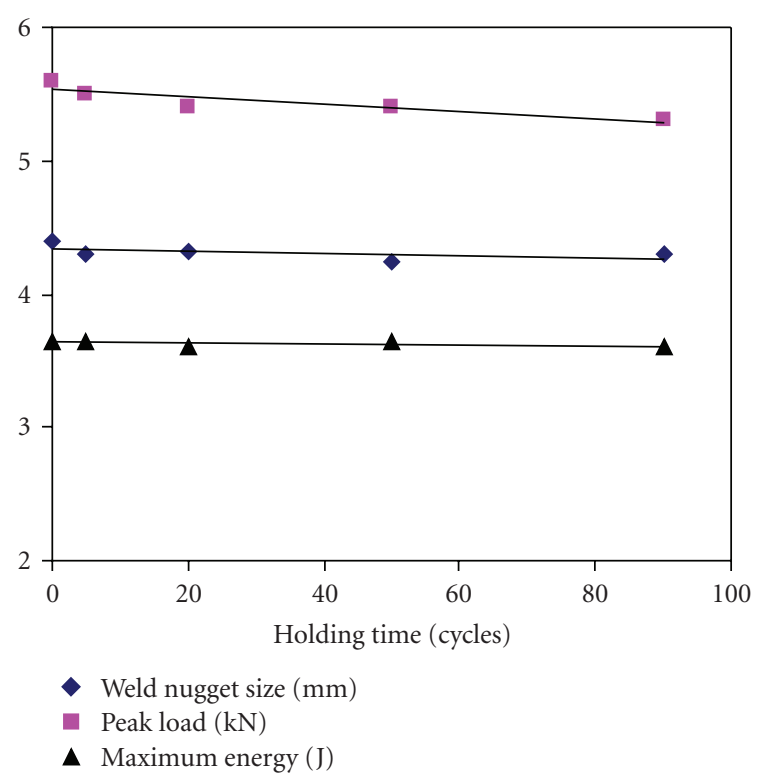

FIGURE 7: Effect of holding time on the weld nugget diameter, peak load, and maximum energy. Welding current is $8 \mathrm{kA}$, welding time is 8 cycles, and electrode pressure is 3 bar.

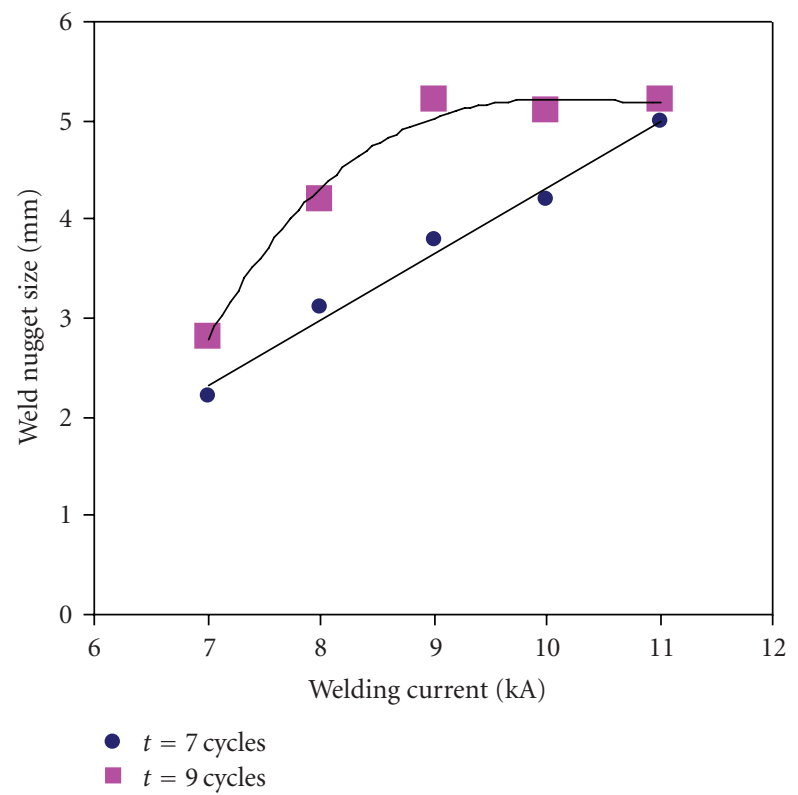

FIGURE 8: Effect of welding current on the weld nugget size (electrode pressure is 3 bar).

current reduces required time to reach melting temperature and, therefore, increases holding time at this temperature (or higher temperatures). Thus, higher volume of the material can exceed liquidus temperature which means that a bigger nugget is formed. Nugget diameter variation rate from zero to maximum, at expulsion, is not uniform. As can be seen in Figures 8 and 9, the slope of nugget diameter versus welding current curve is not uniform for $t=9$ cycles. Also nugget diameter versus welding time curve is not uniform.

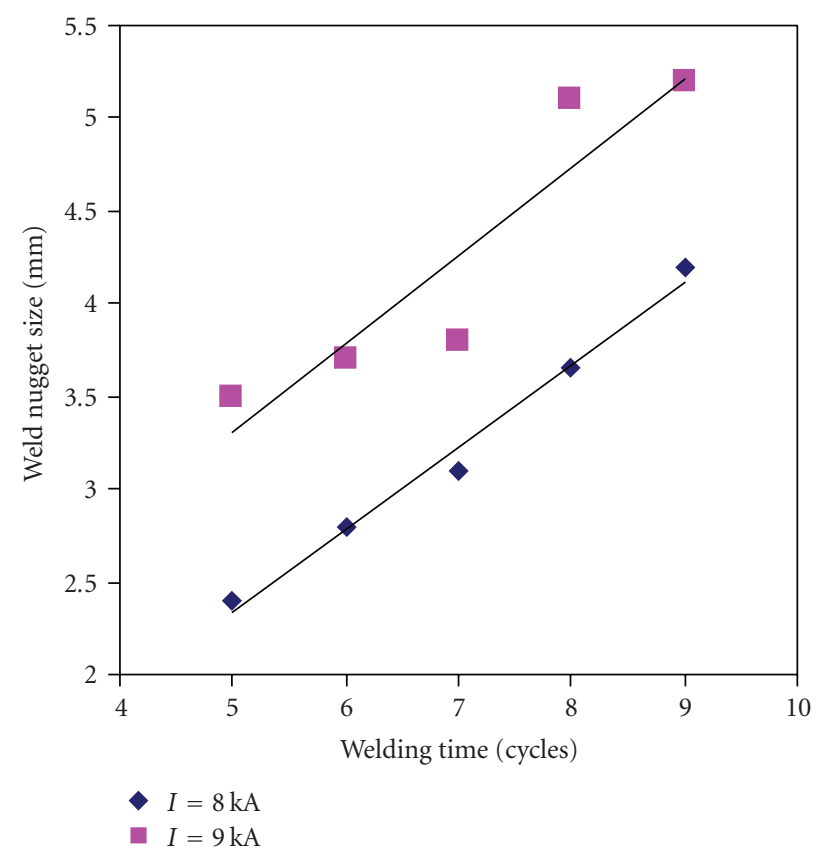

FIGURE 9: Effect of welding time on the weld nugget size (electrode pressure is 3 bar).

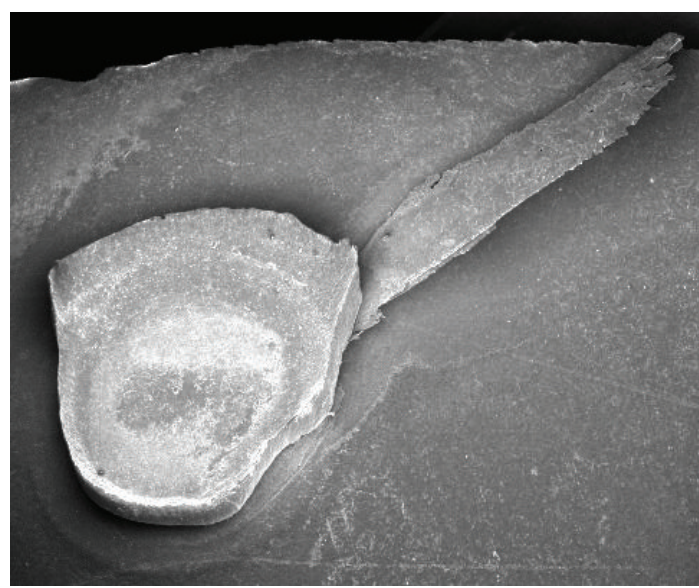

FIgURE 10: Expulsion.

In the high welding current and high welding time regions, expulsion occurs (Figure 10)

According to Gould [6], weld nugget growth as a function of welding current and welding time occurs at four stages as follows:

(i) incubation stage: no melting occurs and weld nugget is not formed,

(ii) nugget formation and rapid nugget growth stage,

(iii) slow nugget growth rate stage,

(iv) expulsion.

Indeed, weld nugget growth rate is affected by two phenomena: increase in electric resistance due to increasing the metals temperature and decrease in electric resistance 


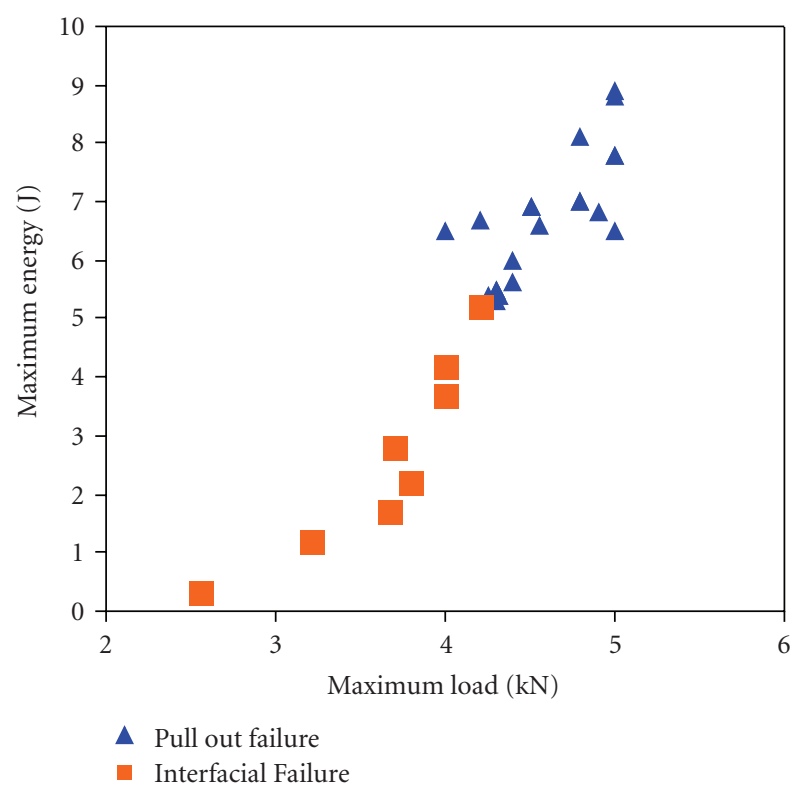

FIgURE 11: Maximum energy versus peak load for interfacial and pullout failure modes.

due to weld nugget formation and its growth. At early stages of weld growth, at which weld nugget is small, resistance increase due to heating material (because of welding current or welding time) overcomes resistance decrease due to weld nugget growth. However, increasing weld nugget diameter increases the effect of resistance decrease caused by weld nugget growth. Therefore, weld nugget growth rate decreases by further increase in welding current or welding time.

\subsection{Effect of Failure Mode on the Weld Performance. Failure} mode is a qualitative criterion for weld quality. In general, spot welds fail in two modes: interfacial and pullout. In interfacial failure mode, failure occurs by crack propagation through weld nugget, while in pullout mode, failure occurs by weld nugget being completely or partially pulled out of the metal sheet.

Effect of failure mode on the $P_{\max }$ and $W_{\max }$ is shown in Figure 11. As can be seen, failure mode has strong effect on weld peak load and maximum energy. Maximum energy and maximum load have less value for interfacial failure mode compared to pullout mode. Typical spot weld fracture surfaces for interfacial and pullout failure modes are shown in Figure 12. As can be seen, almost no plastic deformation is observed for interfacial failure mode, while pullout mode accompanied by considerable plastic deformation found, that at low welding current and welding time, failure occurs in interfacial (shear) mode. Increasing welding current and welding time increases weld nugget diameter and, thus, changes the failure mode to pullout mode. Holding time does not affect weld nugget size and failure mode. Increasing electrode pressure causes excessive reduction of weld nugget size and changes failure mode from pullout to interfacial.

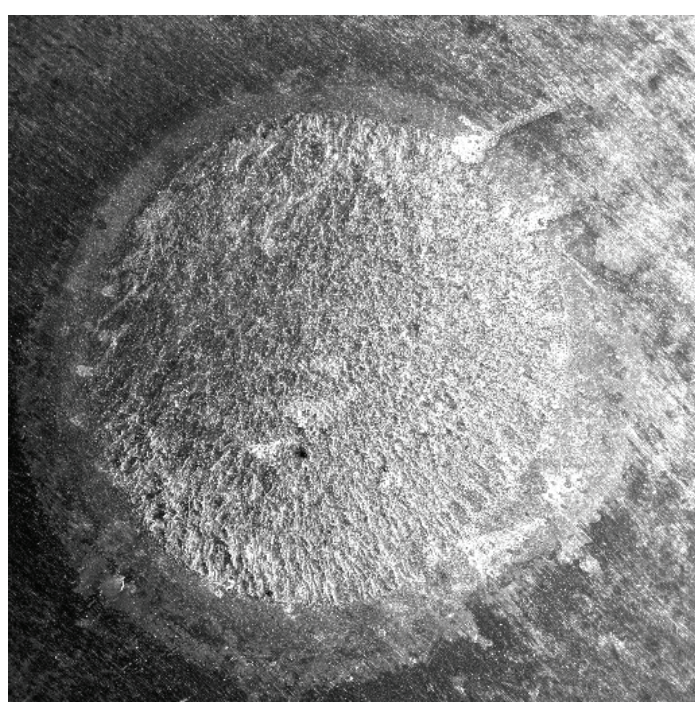

(a)

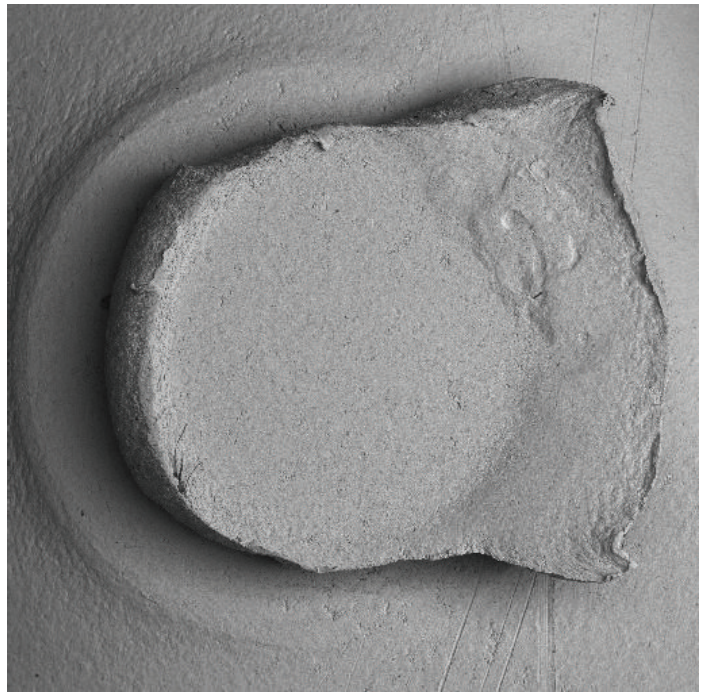

(b)

FIGURE 12: Failure modes: (a) interfacial mode in which failure occurs via crack propagation through weld nugget (b) pullout in which failure occurs via nugget withdrawal from one sheet.

3.4. Effect of Process Parameters on Peak Load and Energy Absorption. Peak load $\left(P_{\max }\right)$ and maximum energy absorption $\left(W_{\max }\right)$ of spot welds depends on their physical characterizations especially weld nugget size and failure location strength [7]. Peak point in load-displacement plot of tensileshear test corresponds to the point of crack propagation through weld nugget for interfacial mode and to necking point at failure location for pullout mode. For interfacial mode, the bigger the nugget size the higher is the interfacial resistance to shearing. For pullout mode, increasing nugget diameter increases nugget resistance against twisting and therefore, increases the required force for necking at failure location. In both cases, increasing weld nugget diameter increases required force for failure to occur. As can be seen in Figure 6, increasing electrode pressure decreases weld 


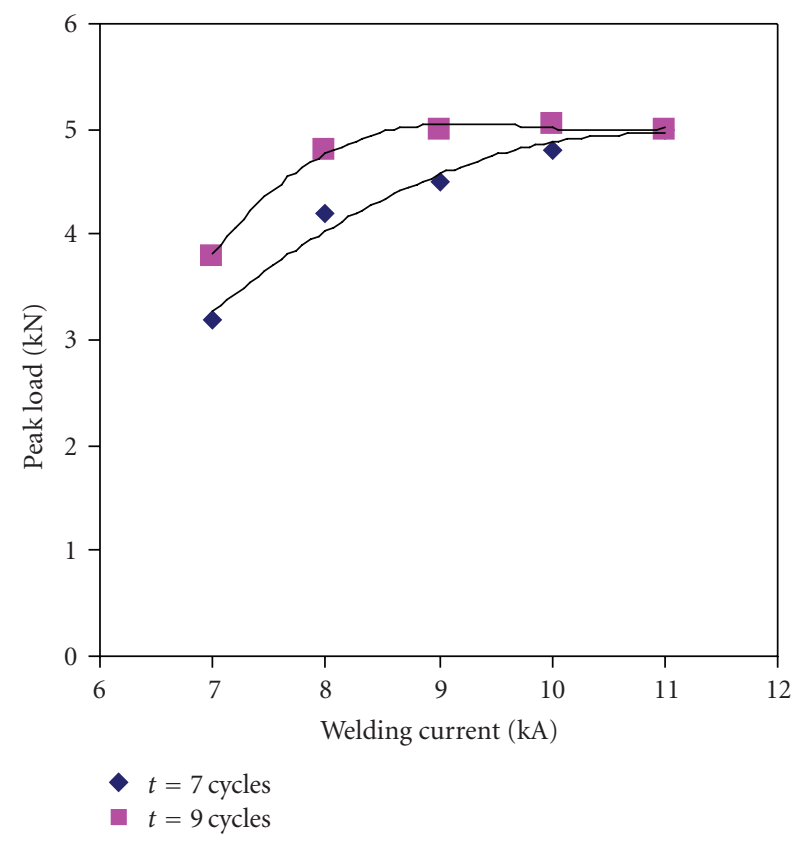

FIGURE 13: Effect of welding current on the peak load (electrode pressure is 3 bar).

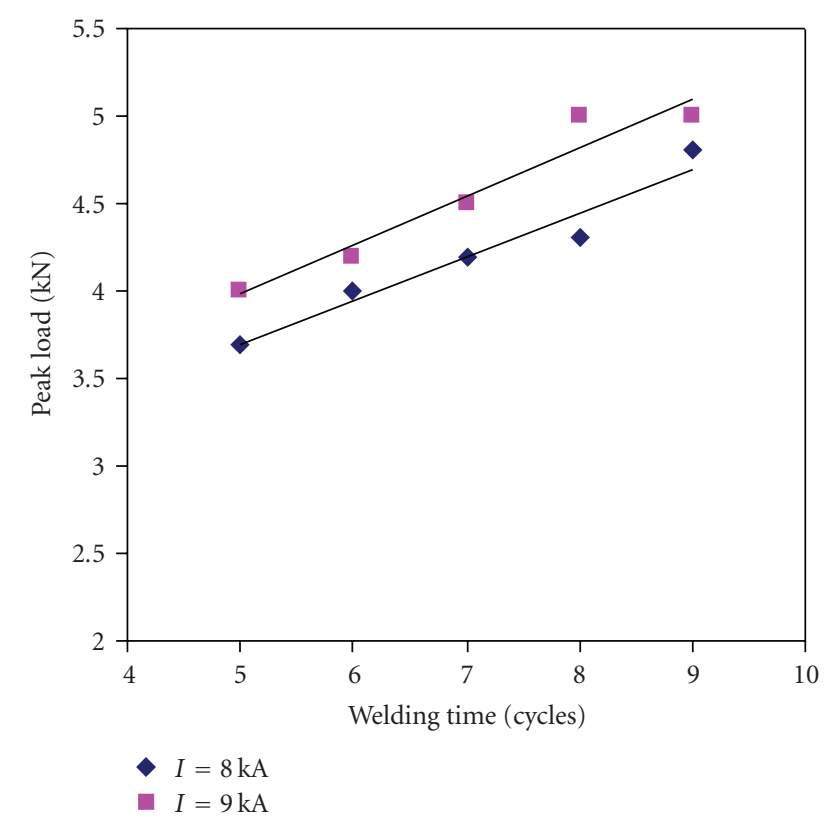

FIGURE 14: Effect of welding time on the peak load (electrode pressure is 3 bar).

nugget size and therefore, spot weld peak load and energy absorption. Holding time increase does not significantly affect peak load and energy absorption (Figure 7). As can be seen in Figures 13 and 14, increasing welding current and welding time increases spot weld peak load as a result of increased nugget diameter. As can be seen in Figures 13 and 14 , at high current region at $t=9$ cycles and at high welding times region at $I=9 \mathrm{kA}$, welding nugget diameter and

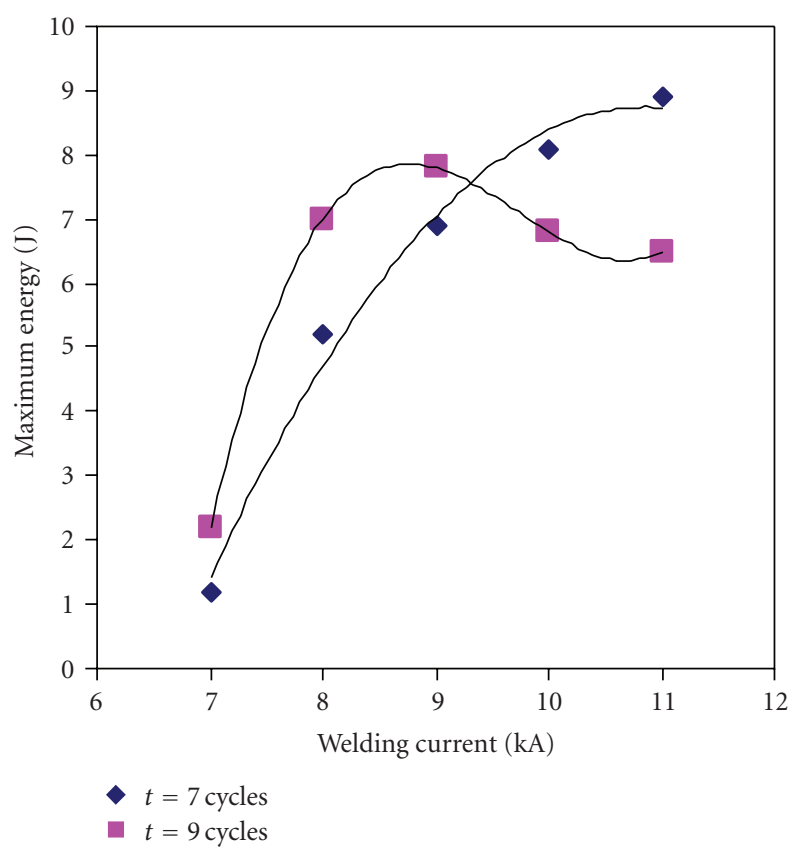

FIGURE 15: Effect of welding current on the maximum energy (electrode pressure is 3 bar).

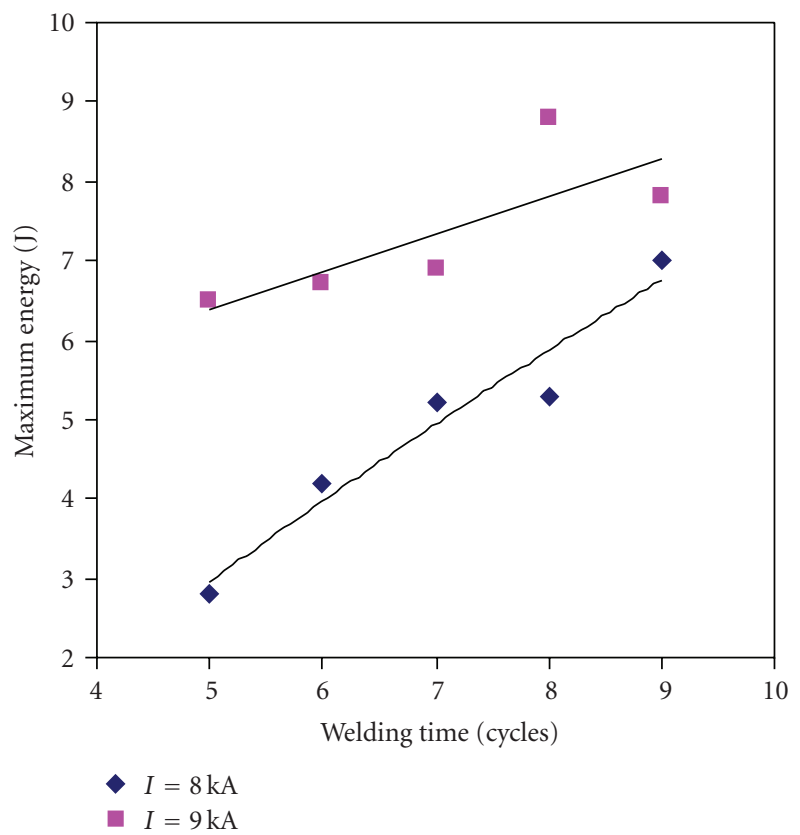

Figure 16: Effect of welding time on the maximum energy (electrode pressure is 3 bar).

thus weld strength are independent of welding parameters. Figure 15 shows maximum energy variations versus welding current for two welding time. As can be seen, for $t=7$ cycles, maximum energy increases with increasing welding current. While, for $t=9$ cycles, increasing welding current increases maximum energy up to a critical point, after which it reduces to even lower than the values corresponding to lower welding time ( $t=7$ cycles). Maximum energy 
variations with welding time for two constant currents are shown in Figure 16. When expulsion occurs, $W_{\max }$ decreases despite constant weld nugget diameter.

High electrode indentation associated with expulsion is the main reason for reduced failure energy at high welding currents and welding times. Electrode indentation affects failure location, and samples experiencing expulsion fail at weld nugget edge. Weld ductility for these samples is less than its value for those samples fail at base metal due to weld nugget edge higher hardness. Therefore, failure at weld nugget edge accompanies less energy absorption. Therefore, maximum energy for those welds showing expulsion is less than expulsion free welds with similar or even smaller weld nugget diameters.

Therefore, contrary to some reports on negligible effect of expulsion on weld performance, it can be seen that although expulsion does not have significant affect on weld strength, it does reduce failure energy. Therefore, if merely $P_{\max }$ is used to describe weld mechanical behavior, the negative effect of expulsion cannot be detected. However, in addition to weld geometrical characterizations such as weld nugget, expulsion can also significantly affect resistance spot weld performance.

\section{Conclusion}

From this study, the following conclusion can be drawn.

(1) In addition to peak load, maximum energy should be considered to more precisely describe spot welds mechanical behavior and performance.

(2) Excessive electrode pressure can reduce both peak load and maximum energy, considerably.

(3) Holding time does not significantly affect peak load and maximum energy for investigated material.

(4) Increasing welding time and welding current to some extent increases both peak load and maximum energy. However, excessive welding time and welding current not only do not increase weld nugget size and peak load, but also decrease maximum energy.

(5) Although expulsion might not decrease spot weld load carrying capacity, it could reduce their energy absorption capability. $W_{\max }$ for samples experiencing expulsion is lower compared to expulsion free samples with identical or even smaller weld nugget size.

\section{References}

[1] N. T. Williams and J. D. Parker, "Review of resistance spot welding of steel sheets-part 1: modelling and control of weld nugget formation," International Materials Reviews, vol. 49, no. 2, pp. 45-75, 2004.

[2] M. Zhou, H. Zhang, and S. J. Hu, "Critical specimen sizes for tensile-shear testing of steel sheets," Welding Journal, vol. 78, no. 9, pp. 305s-313s, 1999.

[3] M. Volger, Investigation of resistance spot weld formation, Ph.D. thesis, Stanford University, Palo Alto, Calif, USA, 1993.
[4] J. E. Gould, S. P. Khurana, and T. Li, "Predictions of microstructures when welding automotive advanced high-strength steels," Welding Journal, vol. 85, no. 5, pp. 111s-116s, 2006.

[5] Q. Song, W. Zhang, and N. Bay, "An experimental study determines the electrical contact resistance in resistance," Welding Journal, vol. 85, no. 5, pp. 73s-76s, 2005.

[6] J. E. Gould, "An examination of nugget development during spot welding using both experimental and analytical techniques," Welding Journal, vol. 66, no. 1-s, 1987.

[7] M. Pouranvari, H. R. Asgari, S. M. Mosavizadch, P. H. Marashi, and M. Goodarzi, "Effect of weld nugget size on overload failure mode of resistance spot welds," Science and Technology of Welding and Joining, vol. 12, no. 3, pp. 217-225, 2007. 

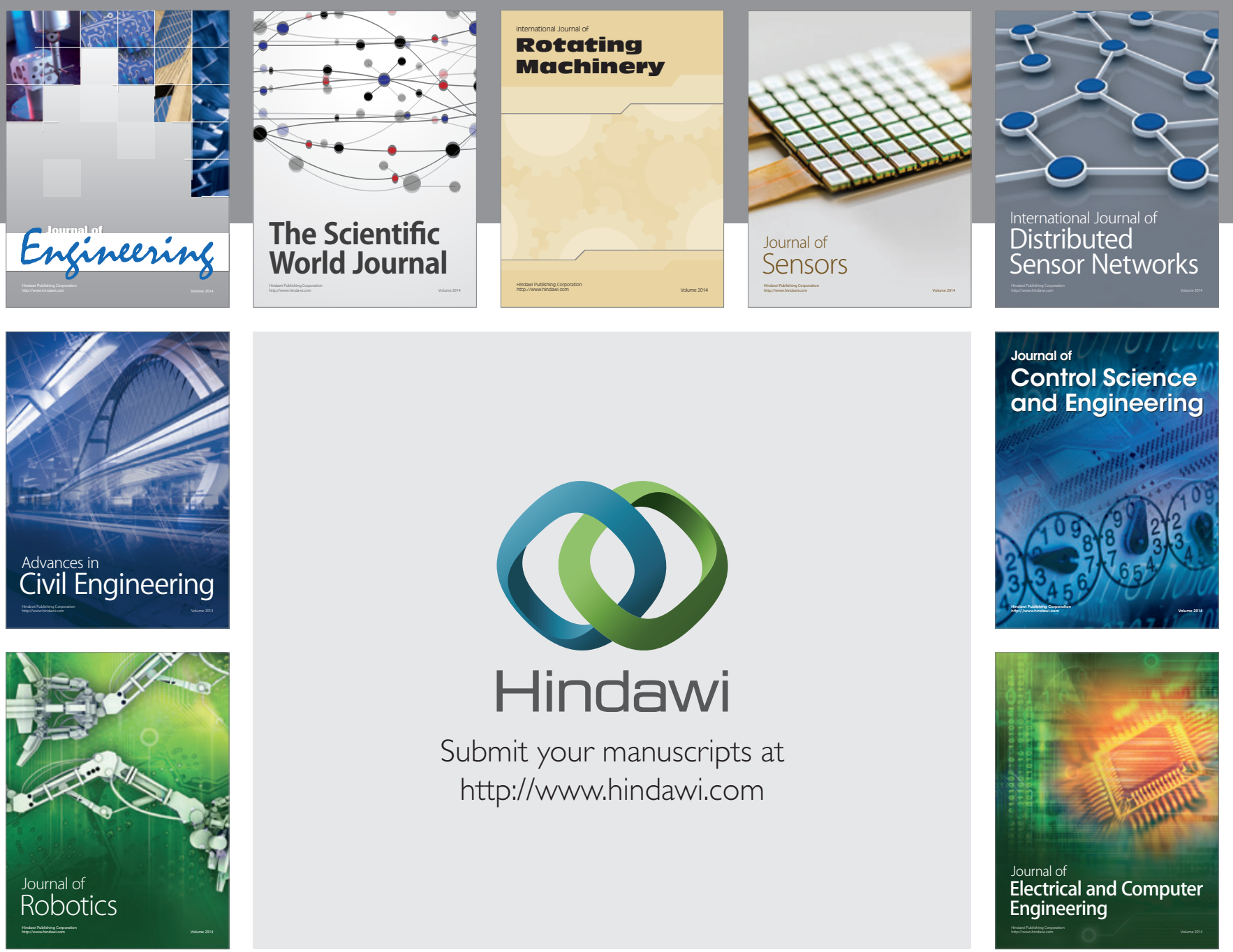

Submit your manuscripts at

http://www.hindawi.com
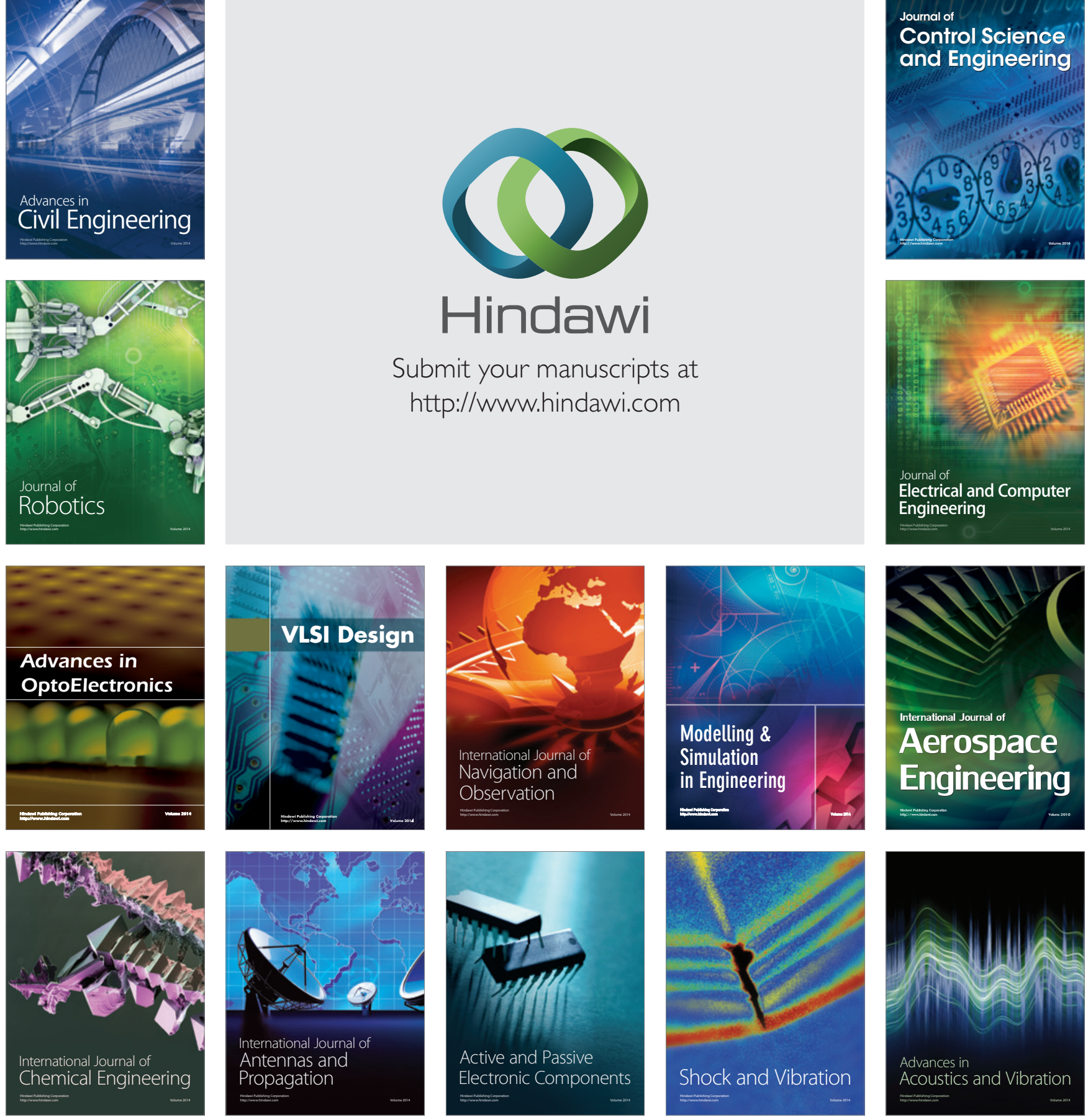